\title{
Examining the demographic profile and attitudes of citizens, in areas where organized crime groups proliferate
}

\author{
Stuart Kirby ${ }^{1}$ (D) Michelle McManus ${ }^{1}$. \\ Laura Boulton ${ }^{1}$
}

Published online: 19 December 2017

(C) The Author(s) 2017. This article is an open access publication

\begin{abstract}
Whilst studies refer to the community impact of Organized Crime (OC), no survey currently exists to examine the views of those citizens who reside in areas where Organized Crime Groups (OCGs) proliferate. 431 questionnaires from households coexisting in high density OCGs areas were analysed in relation to: a) demographic information; b) views on the community and the police; and c) how they expected other residents to react to illegal incidents. Overall respondents thought the average citizen would refuse to intervene in $10 \%-48 \%$ of illegal incidents, with the specific case influencing whether and how they would respond. The analysis then compared three communities who lived in high density OCG areas with a control community $(n=343)$. The 'OCG' communities were more likely to report low collective efficacy and were generally least likely to expect their neighbours to confront a crime in action. Conversely, whilst the control group showed higher levels of collective efficacy and expected the average resident to be more likely in confronting illegal behaviour, this trend did not extend to street drug dealing and serious crime associated with OC. The study discusses the unreported intimidation associated with OCGs and the challenges of policing hostile environments.
\end{abstract}

Keywords Organized crime $\cdot$ Organized crime groups $\cdot$ Collective efficacy

\section{Introduction}

Organized Crime is an enduring and evolving phenomenon, and its impact on local communities is increasingly reported. Unfortunately, the hidden nature of organized

Stuart Kirby

Skirby1@uclan.ac.uk

1 School of Forensic \& Applied Sciences, University of Central Lancashire, Preston, UK 
crime, coupled with the methodological and physical challenges of academic scrutiny, makes the subject difficult to research (von Lampe 2017). Empirical research often revolves around secondary data, such as that collected by the police, and there is an absence of community surveys on the topic. For these reasons, many commentators argue little is known about how organized crime operates in practice (Levi \& Maguire, 2004:397). However, in the UK, the Organised Crime Group Mapping project (OCGM) provides greater insight as to where OCGs concentrate and the threat they pose. This study uses this information to better understand the communities in which OCGs reside.

\section{Literature review}

Empirical research generally starts with a clear understanding as to what is being studied and measured. However the definition of Organized Crime is ambiguous and contested. The meaning, structure and form of OC has been continually debated and dissected (van Dijck 2007, b), generating nearly 200 definitions and a considerable body of literature (von Lampe 2017). This academic ambiguity is mirrored by practitioners. For example, the latest UK strategic assessment has conceptualized (and recategorised) the genre into: commodity, vulnerability and prosperity factors (NCA, 2017). This assessment (as other studies) uses labels interchangeably, with OCGs often referred to as gangs and networks. Whilst these definitional debates are documented more thoroughly elsewhere (Finkenauer 2005), it is clear the interpretation of 'organized crime' can vary between studies, creating difficulties when attempting to replicate or measure findings. This confusion also extends to community studies. Often community perspectives are revealed through intermediaries (i.e. police or community representatives), providing limited clarity on how the community perceive or define OC. These concerns will be returned to later, however as a means of moving forward, this article will use the UK government definition of OC, described as, 'Serious crime, planned, co-ordinated and conducted by people working together on a continuing basis. Their motivation is often, but not always, financial gain' (Home Office 2013: 14). More recently the term Organized Crime Group has been further clarified as a group that a) has as its purpose, or as one of its purposes, the carrying on of criminal activities, and b) consists of three or more persons who act, or agree to act, together to further that purpose (S.45, Serious Crime Act, 2015).

Turning the spotlight onto communities, it is evident they are not created equally, with levels of deprivation, health, employment, education, population, and crime all distributed disproportionally (Bolling et al. 2007; Clarke and Eck 2003; Hales et al. 2009). Indeed, international studies argue that 3-6\% of micro-spaces (individual addresses and street segments), experience $50 \%$ of crime, often combining to form hot spots (Sherman et al. 1989; Kennedy et al. 2010). These geographic crime patterns were identified as early as the 1940's in Chicago. Here it was established that sociostructural and cultural conditions created a neighbourhood effect, from which distinct communities could be differentiated on grounds of deviancy (Shaw and McKay 1942). High negative environmental stimulus (drunks or itinerants in public spaces, noisy parties, youths on street corners, loud music, graffiti and litter), were also found to generate crime signals which created higher levels of fear (Innes and Fielding 2002). 
Whilst most community studies focus on general categories of crime and disorder there is a small but growing body of evidence that highlights the local impact of OC (Kirby et al. 2016). A telephone survey involving 1000 residents, between 2004 and 2006 , on behalf of the UK government, found $70 \%$ of respondents thought the problem of OC was serious and had escalated over the two years (Bullock et al. 2013). The study also illustrated that respondents were more concerned with the personal localized threat emanating from OC, rather than the wider impact at society or national level. This local dimension of OC is well documented by a number of studies. Crocker et al. (2017) discovered UK OCG members offended in their local area as well as further afield. Further, a Dublin study discovered crime families could dominate residential areas and 'acted to encourage and compel certain young people into abnormal patterns of criminal behaviour' (Dept of Children and Youth Affairs, 2016:4). There also appears a link between residential areas associated with deprivation / debt and a range of OC offences, including: drug markets (Lupton et al. 2002); illicit tobacco distribution (Frone, 2013); corruption (Harocopos \& Hough, 2005); and sex markets (May et al. 1999). Lupton et al. (2002) argued that local customers are often complicit in the success of illicit markets. For example, social acceptance of counterfeiting is high across Europe even though the crime is linked to terrorism and drug/human trafficking (De Barnier 2014). The negative impact of OC in local communities is said to include: the generation of inappropriate role models to young people (Hales \& Hobbs, 2010); discarded drugs paraphernalia; and public disorder in the form of beatings and shootings (Crocker et al. 2017). Further, OCG behaviour is said to create a 'pervasive atmosphere of fear and menace', which deters residents from co-operating with the Criminal Justice System (Crocker et al. 2017:29). These factors impinge on community confidence, damage community reputation, and make regeneration more difficult (Lupton et al. 2002).

Numerous studies in the general field of crime and disorder have emphasized how communities can counteract this threat. One of the more influential theories, known as 'broken windows', argues small misdemeanors, if left unchecked, can escalate to more serious problems (Wilson and Kelling 1982). This explanation underlines the importance of community cohesion and collective efficacy, which highlights the importance citizens have in making their locality more resilient to crime and disorder, by refusing to accept antisocial norms (Cantle, 2001; Sampson 2004). The logic is that areas which show a high level of social integration and trust between residents: a) engender a high level of motivation in achieving positive community goals; b) apply a high level of informal policing to the area; c) be more willing to assist and work alongside the police; and d) ultimately be associated with areas that have lower levels of crime and disorder (Bottoms 2012).

This understanding has helped to shape policing tactics on both sides of the Atlantic in the form of the Chicago Alternative Policing Strategy (Skogan and Hartnett 1997), and the UK National Restoring Reassurance Project (later evolving into the UK Neighborhood Policing programme) (Innes and Fielding 2002). Underpinning each was a realization that the public were less concerned about police crime statistics than the visible representation of incivility and intimidation in their neighborhood (vandalism, discarded hypodermic syringes). The solution was to provide identifiable and accessible neighborhood officers who identify and prioritise community concerns, coordinate multi-agency and community interventions, and provide community updates. 
A UK evaluation found public confidence increased and crime was reduced (Tuffin et al. 2006). However, although the community were central, they were generally viewed as homogenous, with little systematic or scientific assessment of their diversity. Conversely, recent U.S. research has attempted to conceptualize the resilience of local communities under the label of 'situational policing' (Corkrean 2013). Here, geographic communities have been divided into three categories: a) 'dependence', epitomized by residents who rely solely on the police to deal with their problems; b) 'conflict', which describe those who are antagonistic and neither ask for help from the police, nor aid them; and c) 'interdependence', where the residents rely on each other to uphold community values, norms and legislation. This latter category is associated with a strong and resilient community that is more likely to be resistant to potential criminality.

Whilst Harocopos \& Hough (2005) highlighted the need to respond to the threat of OC by surveying community views; this approach remains absent due to the methodological challenges surrounding it. Indeed, as an illustration, a recent extensive study looking at the local impact of OC across three UK cities, was based on 210 semistructured stakeholder interviews, of which only 13 were from community based organizations (Crocker et al. 2017). In contrast, this study directly asks residents about crime, their community, and the police.

\section{Methodology}

This study was conducted with the assistance of representatives from one of the largest UK police forces, responsible for policing a metropolitan city and suburbs, with a population of over two million. The researchers were subjected to a national vetting process and met analysts and practitioners (at both strategic and tactical level), to develop a greater understanding of the area and police activity within it.

OC research generates numerous methodological challenges and this study faced similar difficulties. The survey design and administration was assisted by advice from US academics (experienced in surveying police agencies), and representatives from the police agency involved. As a specific example, it was argued 'organised crime gangs' would be a more understandable term for community residents than the official UK label of 'organised crime group'. The 28 question survey (see Fig. 1) was divided into three sections. Questions 1-10 asked for personal details in relation to the respondent, the type of area they lived within, and their experience of victimisation. Questions 1928 asked general questions surrounding their neighbourhood, the residents and their relationship with the Police. Questions 11-18 presented the respondent with several unambiguous scenarios relating to crime or disorder, (with questions 17 and 18 asking specific questions about Organised Crime). All of these questions asked how the average resident (rather than themselves) would respond. Posing the question in this way was thought to minimize the interpersonal factors associated with individual decision making and generate more insight into community opinion. 


\section{COMMUNITY QUESTIONNAIRE}

This voluntary and anonymous survey is being undertaken by [name police force] in an attempt to understand how members of the community perceive crime in their local area. The findings will be independently analysed by researchers at [name University]. The results will assist [name police force] understand how they can work more effectively with the community and local agencies, in your area, to tackle crime and anti-social behavior. If you have any questions about this questionnaire you can contact [details representatives from police force and university]

Some details about yourself (providing these details assist in understanding how different sections of the public perceive the issues).

1. Are you a) Male or b) Female

2. Please highlight your age category: a) $18-24$; b) $25-34$; c) $35-44$; d) $45-54$; e) $55-64$; f) over 65.

3. How long have you lived at your current address: a) less 6 months; b) $6-11$ months, c) 1-3 years; d) 4 or more years.

4. How many people currently live in your household? a) I live alone; b) 2-3 people; c) 4-6 people; d) over 6 people.

5. Have you been the victim of a crime?: a) l've never been a victim of crime; b) yes, I've been a victim of crime within the past 6 months; c) yes, between 6 months - 1 year; d) yes, I was a victim of crime over 1 year ago.

6. If you have experienced a crime, did you report the most recent incident(s) to the Police: a) yes; b) no; c) I generally report the incident; d) I generally don't report the incident to the police.

7. Has anyone in your household been a victim of crime? a) never; b) yes, within the past 6 months; c) yes, between 6 months - 1 year; d) yes, over 1 year ago.

8. When was the last time you had contact with [local police force]? a) last month, b) last year, c) over a year ago, d) l've never had contact.

\section{The area you live (your neighbourhood)}

9. When you or other people refer to your local neighbourhood or area, what do you understand by this? a) 1 or 2 streets; b) 2-10 streets; c) 11 streets or more; d) a larger area which would take a specific amount of minutes to walk from one end to another (please specify time in minutes); e) other description (please specify).

10. How many immediate neighbours do you know by name? a) none b) I know the neighbours names on one side of my house; c) on both sides of my house; d) on both sides and opposite; e) I know nearly all the people in my immediate neighbourhood by name.

\footnotetext{
Keeping in mind the area you refer to as your 'neighbourhood' (or local area), how do you think the average resident is most likely to act in the following situations? Please highlight the most likely response:

11. They see children who they think are playing truant

a) Intervene personally and speak to the children

b) Together with other neighbor(s) go and speak to the children

c) Inform the children's parents or guardians

d) Meet with other residents to try and establish what can be done to reduce the problem

e) Inform the school
}

Fig. 1 
f) Inform the police

g) Nothing, they would not intervene.

h) They would do something else (please describe)

12. They see children spraying a wall with graffiti
a) Intervene personally and speak to the children
b) Together with other neighbor(s) go and speak to the children
c) Inform the children's parent(s) or guardian(s)
d) Meet with other residents to try and establish what can be done to reduce the problem
e) Inform their school
f) Inform the police
g) Nothing, they would not intervene.
h) They would do something else (please describe)

13. They see teenagers fighting in the street

a) Intervene personally and speak to the teenagers

b) Together with other neighbor(s) go and speak to the teenagers

c) Inform the teenager's parent(s) or guardian(s)

d) Meet with other residents to try and establish what can reduce the problem

e) Inform their school

f) Inform the police

g) Nothing, they would not intervene.

h) They would do something else (please describe)

14. They see a person, who they don't recognize, acting suspiciously within the confines of a neighbours property
a) Intervene personally and speak to the person
b) Together with other neighbor(s) go and speak to the person
c) Inform the relatives / friends of the house owner
d) Meet with other residents to try and establish what to do about suspicious activity
e) Inform the police
f) Nothing, they would not intervene.
g) They would do something else (write it here)

15. They see a resident from their street being assaulted or threatened by a current or ex-partner:
a) Intervene personally and speak to the individuals involved
b) Together with other neighbour(s) go and speak to the victim / assailant
c) Inform the relatives/ friends of the victims in an attempt to stop them
d) Meet with other residents to try and establish what can reduce the problem
e) Inform the police
f) Nothing, they would not intervene.
g) They would do something else (write it here)

16. They see drug dealing occurring on their street corner:
a) Intervene personally and speak to the individuals involved
b) Together with other neighbour(s) go and speak to the people involved
c) Inform the parents or relatives of the individuals involved

Fig. 1 (continued) 

d) Meet with other residents to try and establish what can be done to reduce the problem
e) Inform the police and provide their own personal details
f) Inform the police anonymously or call Crimestoppers (anonymous call line)
g) Nothing, they would not intervene.
h) They would do something else (write it here)

17. They hear about an organised crime gang living in the neighbourhood, who manufacture and deal in counterfeit goods
a) Intervene personally and speak to the individuals involved
b) Together with other neighbour(s) go and speak to the people involved
c) Call the relatives / friends of the individuals involved in an attempt to stop them
d) Meet with other residents to try and establish what can be done to reduce the problem
e) Inform the police and provide their personal details
f) Inform the police anonymously or call Crimestoppers (anonymous call line)
g) Nothing, they would not intervene.
h) They would do something else (write it here)

18. They hear about an organised crime gang living in the neighbourhood, who deal in class A drugs (e.g. heroin and cocaine)
a) Intervene personally and speak to the individuals involved
b) Together with other neighbour(s) go and speak to the people involved
c) Call the relatives / friends of the individuals involved in an attempt to stop them
d) Meet with other residents to try and establish what can be done to reduce the problem
e) Inform the police and provide their personal details
f) Inform the police anonymously or call Crimestoppers (anonymous call line)
g) Nothing, they would not intervene.
h) They would do something else (write it here)

\section{We would now like to ask you some general questions about your perception of safety in your local area}

19. Generally speaking, how safe do you feel walking outside at night in your neighborhood (local area)?
a) Very safe
b) safe
c) unsafe
d) very unsafe

20. How does your neighbourhood (or local area) generally compare with other neighborhoods in [city]
a) It is safer
b) It is about the same as other neighborhoods
c) It is more dangerous

21. What would you say are the 3 biggest problems of crime or disorder that you face in your neighborhood?

Fig. 1 (continued) 


\section{We would now like to ask you some general questions as to your opinion of other residents who live in the neighbourhood, as well as the local police.}

\section{Are you involved in any community groups, if so please list}

For each of the following statements about your neighbourhood, please highlight which one you feel is most accurate

\section{Residents generally trust each other a) I agree; b) I neither agree nor disagree; I} disagree.

24. Residents generally work together to try and reduce community problems: a) I agree; b) I neither agree nor disagree; c) I disagree.

\section{Residents generally trust the Police: a) I agree; b) I neither agree nor disagree; c) I} disagree.

26. Residents generally call the Police to deal with most community problems: a) I agree; b) I neither agree nor disagree; c) I disagree.

27. The effectiveness of the Police in the local area, in terms of reducing crime is: a) very poor; b) fair; c) good; d) very good.

28. The effectiveness of the Police in dealing with problems that really concern local people can be described as: a) very poor; b) fair; c) good; d) very good

Fig. 1 (continued)

A unique aspect of this study was the ability to use neighborhoods known to have a higher saturation of resident Organized Crime Groups (OCGs) and supplement these with a further control area. The police force was able to identify these areas using 'Organised Crime Group Mapping' (OCGM), a procedure where (for nearly a decade), each police agency in England and Wales has counted each OCG in their jurisdiction and assessed its threat (Gilmour 2008). The process also allows the UK Home Office to aggregate the data at a national level, using a scale of low (1) to high (5) (Home Office 2013:23). Whilst the London metropolitan area is unique with a score of 5, the police agency assisting in this study was graded as 4, which depicts a higher than average concentration of OCGs.

Establishing a suitable control area was also problematic. The police representatives involved were asked to identify a location which would mirror as close as possible the characteristics of the other areas, without replicating their OC footprint. Once chosen the similarity of these geographic areas were assessed using the index of multiple deprivation, a UK government calculation which examines locations on: employment; crime; health; education skills and training; barriers to housing and services; and living environment (based on air quality, housing stock and road safety), to form an overall score (DEFRA 2015). All areas (including the control site) show a very similar profile, being urban residential areas, and whilst each scored reasonably well in relation to living environment, all had a poor overall deprivation score (the OCG areas were within the bottom 1-3\% of deprived areas nationally, and the control area within the bottom 6\%). Questionnaire responses also illustrated few demographic differences across the communities (age, number in household, settled residence). The police officers asked that the sites remained anonymous to avoid stigmatization. 
A further methodological challenge related to delivery and collection of questionnaires. To reduce cost and endorse the legitimacy of the process to residents the surveys were hand delivered by Police and Community Support Officers (PCSOs) during normal patrol duties. PCSO's are non-sworn officers primarily engaged on low level, non-confrontational, community policing issues. Prior to delivery the PCSO was asked to place a geographic mark on the questionnaire identifying the community to which it had been delivered. The packs were self explanatory and no communication was necessary or requested. Each pack explained the reasons behind the voluntary and anonymous questionnaire, and stated the data would be analyzed by independent academics. Approximately a fortnight later the officers started to collect the completed questionnaires in sealed envelopes (supplied). These were returned over a period of weeks and some of the questionnaires were handed into the local police station. Unfortunately, the return rate is unknown as the number of distributed questionnaires was not systematically captured. Indeed, two of the areas returned much fewer forms than the rest, and some forms were returned with no geographic identifier. As will be explored later in this article, this approach has a number of methodological limitations.

\section{Results}

All household questionnaires returned to the researchers were initially analyzed ( $n=$ 431). This was followed by specific geographic analysis to see whether it was possible to distinguish communities on: demographic information; how they viewed their environment; and how they expected neighbours to respond to crime. As two of the chosen communities returned a small number of questionnaires $(n=16 ; n=32)$, and others were returned with no geographic identifier $(n=40)$, these were removed from this stage of the analysis. This left 343 questionnaires for geographic comparison, comprising the control area (an area known to have a low incidence of OCGs, $n=80$ ) and three other areas known to have a higher incidence of OCGs (referred to as: area A, $n=61$; Area B, $n=112$; and Area C, $n=90$. For ease of understanding, the results will be provided in percentages, albeit the sum will not always total $100 \%$ due to a small number of missing answers.

\section{Demographic information}

Overall most household questionnaires were completed by a female $(60 \%)$, rather than a male (38\%). Respondents were distributed across the age range with $23 \%$ over 65 years, $40 \%$ between 45 and 64 years; $18 \%$ between 24 and 44 years; $14 \%$ between 25 and 34 years and $6 \%$ in the 18-24 age category. Although no significant age differences were apparent across the geographic areas, areas B and $\mathrm{C}$ had a higher proportion of returns from females $(68.5 \%$ and $65.2 \%$ respectively), compared to the control area $(46.3 \%), \chi^{2}(6)=16.593, p<.05$.

Overall respondents appeared to live in generally settled residential neighborhoods, with the majority residing at their address for 4 or more years $(75 \%)$, and only $8 \%$ for less than 12 months. Half of households (51\%) were inhabited by $2-3$ people, $31 \%$ having over 4 or more people living at the address, and $19 \%$ living alone. When comparing the geographic locations, areas A, B, and the control area were most likely 
to report 2-3 people residing within the household. Area $\mathrm{C}$ was more likely to report a higher number of residents, whilst area A a slightly larger number of sole occupants, $\chi^{2}$ (9) $=17.460, p<.05$.

$51 \%$ of all respondents referred to their neighborhood as an area within 10 streets of their own address and nearly a third (30\%) reported knowing the names of most people within this area. Only $9 \%$ stated they did not know the names of their immediate neighbors. When comparing the locations, respondents from the control area were more likely to identify their local area within a tight parameter of 2-10 streets $(40.5 \%)$, whereas the other areas viewed their local neighborhood as various distances $\chi^{2}(12)=$ $12.272, p<.05$. Furthermore, the areas could be differentiated in how familiar residents were with their neighbors, $\chi^{2}(12)=24.416, p<.05$. Residents in the control location were more likely to say they knew nearly all of their neighbors (36.3\%), and least likely to say they knew none of them (3.8\%) Conversely, divisions A and C were most likely to state they knew none of their neighbours by name (11.9\% and $11.4 \%$ respectively). Again, these factors may indicate patterns of collective efficacy.

\section{The relationship with crime, other residents, and the police}

Overall, $69 \%$ of all respondents reported feeling 'safe', or 'very safe' walking around their neighborhood at night, with only $5 \%$ feeling their area was more dangerous than surrounding areas. However geographic differences existed, with only about half of area A respondents feeling safe, which was significantly lower than other areas (control $71.3 \%$; B 79.3\%, C 80.9\%). Indeed, $15.8 \%$ of respondents in area A reported feeling 'very unsafe', when walking outside at night (control: $5 \%, \mathrm{~B}: 3.6 \%$ and area $\mathrm{C}: 3.4 \%$ ), $\chi^{2}(3)=21.485, p<.001$. Also, $16 \%$ of respondents in area $\mathrm{A}$ thought their neighborhood was more dangerous than others in the city, compared to the control area $(6 \%)$, area $\mathrm{B}(2 \%)$ and area $\mathrm{C}(1 \%), \chi^{2}(6)=29.429, p<.001$.

$54 \%$ of all respondents reported being a previous victim of crime, albeit only a minority stated they had been victimized within the past year (11\%). 29\% of respondents also reported other household members experiencing crime. Of those victims, $66 \%$ stated they had reported the incident, whilst $26 \%$ stated they had not. Surprisingly respondents from the control group were more likely to report being a victim of crime in the last 6 months, $\chi^{2}(9)=26.338, p<.01$, and more likely to say another resident within the household had been a victim of crime within this period, $\chi^{2}(12)=29.927, p<.01$ (see Table 1 ). Whilst also stating they were more likely to report a crime $(60 \%)$ than other areas $(A=53 \%, B=47 \%, C=49 \%)$, this was not statistically significant.

Whilst most respondents said they had previous contact with the police (14\% in the past month, $17 \%$ in the past year and $42 \%$ over a year ago), $25 \%$ of respondents reported never having had contact. Only $51 \%$ of participants said they would definitely call the police to deal with community problems. $48 \%$ of respondents felt the police did a good, or very good, job at reducing crime, reporting slightly less confidence in their ability to deal with wider neighborhood problems, such as antisocial behavior (46\%). Geographic analysis found those in the control area were most likely to have contacted the local police in the previous month $(22.5 \%)$ compared to areas A $(13.3 \%)$, B $(10.6 \%)$ and $\mathrm{C}(11.6 \%)$, albeit this was marginally non-significant $(p=.056)$. A reverse pattern was also seen, with respondents from areas $\mathrm{A}$ and $\mathrm{C}$ least likely to have 
Table 1 Breakdown of responses by specific geographic area

\begin{tabular}{|c|c|c|c|c|c|}
\hline Variable & Level & $\begin{array}{l}\text { Control } \\
(\mathrm{n}=80) \%\end{array}$ & $\begin{array}{l}\text { Area A } \\
(n=61) \\
\%(n)\end{array}$ & $\begin{array}{l}\text { Area B } \\
(n=112) \\
\%(n)\end{array}$ & $\begin{array}{l}\text { Area C } \\
(n=90)\end{array}$ \\
\hline \multirow[t]{2}{*}{ Gender* } & Male & $53.8 \%$ & $43.3 \%$ & $28.8 \%$ & $33.7 \%$ \\
\hline & Female & $46.3 \%$ & $56.7 \%$ & $68.5 \%$ & $65.2 \%$ \\
\hline \multirow[t]{4}{*}{ Household makeup* } & Alone & $18.8 \%$ & $14.8 \%$ & $18.9 \%$ & $16.9 \%$ \\
\hline & 2-3 people & $56.3 \%$ & $54.1 \%$ & $57.7 \%$ & $40.4 \%$ \\
\hline & 4-6 people & $23.8 \%$ & $26.2 \%$ & $23.4 \%$ & $41.6 \%$ \\
\hline & Over 6 people & $1.3 \%$ & $4.9 \%$ & $0 \%$ & $1.1 \%$ \\
\hline \multirow[t]{2}{*}{ Victim of crime ${ }^{* *}$} & Never been victim & $32.9 \%$ & $55.2 \%$ & $48.2 \%$ & $58.6 \%$ \\
\hline & Victim last 6 months & $10.1 \%$ & $8.6 \%$ & $3.6 \%$ & $4.9 \%$ \\
\hline \multirow[t]{2}{*}{ Household member victim crime ${ }^{* *}$} & Never been victim & $54.4 \%$ & $65.0 \%$ & $68.2 \%$ & $72.9 \%$ \\
\hline & Victim last 6 months & $7.6 \%$ & $6.7 \%$ & $3.6 \%$ & $1.2 \%$ \\
\hline Feelings safety walk outside at night $* * *$ & Safe & $71.3 \%$ & $49.1 \%$ & $79.3 \%$ & $80.9 \%$ \\
\hline \multirow{3}{*}{$\begin{array}{l}\text { Feelings of safety compared to other } \\
\text { neighborhoods } * * *\end{array}$} & Safe & $38.0 \%$ & $14.8 \%$ & $39.6 \%$ & $49.4 \%$ \\
\hline & Same & $55.7 \%$ & $70.4 \%$ & $58.6 \%$ & $49.4 \%$ \\
\hline & More dangerous & $6.3 \%$ & $14.8 \%$ & $1.8 \%$ & $1.1 \%$ \\
\hline Neighbours by name* & Nearly all & $36.3 \%$ & $10.2 \%$ & $34.2 \%$ & $27.3 \%$ \\
\hline Residents trust each other** & Agree & $76.3 \%$ & $40.7 \%$ & $66.1 \%$ & $61.4 \%$ \\
\hline Work together* & Agree & $51.9 \%$ & $28.8 \%$ & $50.0 \%$ & $32.2 \%$ \\
\hline \multirow{2}{*}{$\begin{array}{l}\text { Police effectiveness reducing crime } \\
\text { local area* }\end{array}$} & Good - Very good & $57.0 \%$ & $34.5 \%$ & $55.6 \%$ & $42.0 \%$ \\
\hline & Poor - fair & $43.0 \%$ & $65.5 \%$ & $44.4 \%$ & $58.0 \%$ \\
\hline
\end{tabular}

$* p<.05, * * p<.01, * * * p<.001$

contacted the police (35\% and $34.9 \%$ respectively) when compared with the control area $(15 \%)$.

Trust is a concept often aligned with collective efficacy. In this study $59 \%$ thought residents trusted each other, which was almost identical to their trust of the police (58\%). When comparing geographic areas, residents within the control area were most likely to report they trusted other residents $(76.3 \%)$, in contrast to area A, who were the least likely $(40.7 \%$ ) (Area B: 66.1\%, C: $61.4 \%), \chi^{2}(6)=18.714, p<.01$. Whilst overall $38 \%$ agreed they would work together with residents to reduce community problems, this was most likely reported by respondents within the control area $(51.9 \%)$, with respondents from area $\mathrm{A}$, the least likely $(\mathrm{A}=28.8 \% ; \mathrm{B}=50 \% ; \mathrm{C}=32.2 \%), \chi^{2}(6)=$ $16.139, p<.05$.

Respondents in the control area reported more trust in the police $(65 \%)$, and stated they were more likely to call the police, to deal with community problems $(60 \%)$. Area A recorded the lowest level of trust in the police (49.1\%), and were least likely to contact them with community problems $(45.3 \%)$, albeit these differences were not statistically significant. This finding was mirrored in respondents' view of police effectiveness, $\chi^{2}(3)=10.159, p<.05$. Those within area A were most likely to report police effectiveness in reducing crime was poor-fair $(65.5 \%)$, whereas $78.5 \%$ of those within the control area reported it as good/very good (none reported it was poor). 


\section{How respondents expected residents from their community to respond to crime and antisocial behaviour}

The survey then examined how respondents thought residents from their community would respond to specific incidents of crime or antisocial behavior. Figure 1 provides a full description of these questions and Table 2 provides the responses, for all respondents $(n=431)$ and the geographic comparison $(n=343)$. It is worth highlighting that overall the likelihood of a response, was reliant on the type of crime or incident. Indeed, the likelihood of a resident response could be scaled in the following priority order:

1. A person being seen to act suspiciously around a neighbours property ( $88 \%$ would respond);

2. A resident being threatened/assaulted by a possible ex-partner (85\%);

3. A neighbourhood OCG dealing in class A drugs (e.g.heroin or cocaine) (80\%);

4. Witnessing drug dealing taking place on the street (78\%);

5. Children spraying graffiti $(77 \%)$;

6. Teenagers fighting in the street $(71 \%)$;

7. An OCG dealing in counterfeit goods $(71 \%)$;

8. Children playing truant $(52 \%)$.

As such, interventions were viewed individually, and did not appear to replicate a Criminal Justice sanction scale. So, for example, 29\% of all respondents thought residents would be unwilling to intervene with teenagers fighting in the street (assault), and would also ignore members of an organised crime gang engaged in counterfeiting. The method of resident intervention was also reliant on the specific incident. Overall almost half of respondents thought the average citizen would be willing to personally intervene in a physical way and this was most likely when confronting someone acting suspiciously around a neighbours' property, or a resident being threatened or assaulted by an ex partner (34\% personally intervening in truancy, $45 \%$ graffiti and $29 \%$ youths fighting). However, in relation to the OC associated questions, only $2-3 \%$ of

Table 2 The \% of respondents who feel the average resident would respond in some way to incidents of crime and antisocial behaviour. Results show overall respondent findings and findings according to specific geographic area

\begin{tabular}{llllll}
\hline Variable & $\begin{array}{l}\text { Overall action } \\
\text { taken }(n=431)\end{array}$ & $\begin{array}{l}\text { Control } \\
(\mathrm{n}=80)\end{array}$ & $\begin{array}{l}\text { Area A } \\
(\mathrm{n}=61) \%\end{array}$ & $\begin{array}{l}\text { Area B } \\
(\mathrm{n}=112) \%\end{array}$ & $\begin{array}{l}\text { Area C } \\
(\mathrm{n}=90) \%\end{array}$ \\
\hline Truancy & $52.4 \%$ & $53.2 \%$ & $42.6 \%$ & $53.2 \%$ & $56.8 \%$ \\
Spraying graffiti*** & $78.7 \%$ & $85.9 \%$ & $52.7 \%$ & $84.3 \%$ & $81.6 \%$ \\
Teenagers fighting in street & $73.8 \%$ & $81.0 \%$ & $68.5 \%$ & $75.0 \%$ & $69.0 \%$ \\
Assault partner* & $88.8 \%$ & $94.9 \%$ & $78.2 \%$ & $89.8 \%$ & $88.5 \%$ \\
Suspicious behaviour & $90.6 \%$ & $95.0 \%$ & $85.7 \%$ & $90.7 \%$ & $89.4 \%$ \\
Street drug dealing & $81.0 \%$ & $80.8 \%$ & $70.4 \%$ & $82.2 \%$ & $86.2 \%$ \\
OCG Counterfeit & $73.8 \%$ & $71.4 \%$ & $66.7 \%$ & $70.8 \%$ & $83.9 \%$ \\
OCG involved Class A* & $82.6 \%$ & $81.6 \%$ & $72.7 \%$ & $81.5 \%$ & $91.0 \%$ \\
\hline
\end{tabular}

$* \mathrm{p}<.05, * * * \mathrm{p}<.001$ 
respondents (dependent on the OC category) expected the resident to approach the offender directly. Here action was most likely be an anonymous call to the police. Overall, the least likely response, across each scenario, was to discuss the incident with other residents.

The analysis then examined these decisions across geographic communities. The responses were explored in full, and dichotomously (action / no action), due to the number of cell violations when examining the full range of intervention responses. The control area was significantly more likely to report the average citizen would intervene when observing someone spraying graffiti (Control $=85.9 \%, \mathrm{~A}=52.7 \%, \mathrm{~B}=84.6 \%$ and area $\left.\mathrm{C}=81.5 \%), \chi^{2}(3)=26.935, p<.001\right)$. This finding was replicated in relation to a resident being assaulted/threatened by a current/ex-partner (Control $=94.9 \%$ of cases, $\mathrm{A}=78.2 \%, \mathrm{~B}=89.8 \%$ and $\mathrm{C}=88.6$ ), $\chi^{2}(3)=9.311, p<.025$. (see Table 2 ). $\mathrm{A}$ further question related to people openly selling drugs in their community. Here the pattern changed slightly with respondents from the control area no longer suggesting their residents were the most likely to intervene. Area $\mathrm{C}$ was the most likely to respond $(86.3 \%)$, followed by area B $(82.5 \%)$, and the control area $(81.1 \%)$. Area A $(70.4 \%)$ was reported as the least likely to act.

The final questions referred to two incidents associated with organized crime and responses followed the street drug dealing question. In relation to a local OCG producing or distributing counterfeit goods, respondents from area $\mathrm{C}$ thought their residents were most likely to respond $(83.9 \%)$. This was followed by the control area $(71.5 \%)$, area B $(71.3 \%)$ and area A $(66.7 \%)$, albeit these findings were statistically non-significant. The final question asked how the average resident would react to a neighbourhood OCG dealing in class A drugs (heroin and cocaine). This difference was statistically significant $\left(\chi^{2}(3)=8.268, p<.050\right.$, with area $C$ again appearing most likely to say they would respond $(90.9 \%)$ followed by the control area $(81.6 \%)$ and area B (81.5\%). Again, those in area A $(72.7 \%)$ were the least likely to say they would act.

In summary, respondents from area A consistently reported that the average resident in their location was less likely to intervene overall. Whilst respondents from the control area were more likely to indicate that the average resident would intervene for general crime or antisocial behavior incidents, this confidence was not extended to scenarios of street drug dealing or offences explicitly associated with organized crime.

\section{Discussion}

\section{Limitations of research method}

At the outset, it should be reiterated that numerous methodological issues are associated with OC studies. This is particularly true of community surveys, which no doubt accounts for their absence in the academic literature. There are four specific concerns. First, there is the ambiguity that surrounds the definition of organized crime across academic, practitioner and community sectors. Just as academics have generated nearly 200 separate definitions of organised crime, it can be assumed that respondents also responded to this survey according to their individual perception of OC. Second, it has long been acknowledged that experimenter attributes affect a subject's response (Rosenthal 1963). In this study uniformed police staff distributed and collected the 
questionnaires. Whilst public trust in UK police is at a 34 year high at $71 \%$ (The Gaurdian 2016), respondents surveyed in this study showed a much lower overall figure of $58 \%$. It is thought this lack of trust would have an impact on who responded and how they responded. Third, questionnaires are open to considerable subjectivity and are influenced by both respondent memory and interpretation; indeed the bystander intervention paradigm (Levine et al. 2002) highlights that expected behavior does not always correspond with actual behavior. Finally, the survey only illustrates an association - it is unknown whether the factors linked to concerns surrounding safety and trust, came before or after the emergence of OCGs in that area. It appears evident that more accurate calibration of community profiles (across a range of variables), is needed together with further understanding as to why OCGs concentrate in specific residential areas.

\section{Discussion of findings}

Whilst these methodological concerns highlight the considerable caution that should be taken when interpreting the findings, it is also of concern that organized crime is not reducing and both policy makers / practitioners are increasingly looking for opportunities to stimulate preventative approaches (Kirby and Snow 2016). Understanding the environmental dynamics where OCGs reside is critical in this aim. Therefore, whilst at one level this article can be used to assist others in generating more sophisticated procedures, even with these methodological caveats it is suggested the findings reveal important information to assist future practice and stimulate research. It should also be recognized that community surveys provide: a wider perspective; can prevent the interviewer bias associated with semi-structured interviews; delivers a quantitative response that can be tested for statistical significance; and generates a more consistent benchmark that can be revisited over time.

Although the geographic distribution of crime and disorder is well established, the informal role of residents, and their impact on crime and disorder is less developed (Weisburd et al. 2015). Nonetheless researchers have highlighted the importance of concepts such as social disorganization and collective efficacy (Sampson and Groves 1989; Kubrin and Weitzer 2003). This argues that if a community is insular and apathetic to crime, then antisocial behavior is more likely to thrive. Conversely, if a community works together and in partnership with the police, the incidence of crime can be reduced. Whilst previous community studies have focused on low level crime and antisocial behavior this study has been able to introduce the influence of organised crime. It did so in two ways: first, by identifying OCG concentration in a specific area using the UK organised crime group mapping project; and second, through introducing OC related questions in the community survey. The results highlight three points of interest.

First, the index of multiple deprivation and questionnaire responses show residents living in relatively similar, well established urban residential areas, could be differentiated on their attitudes towards their community, the police, and crime. For example, respondents in the control area showed higher indicators of collective efficacy (trust, engagement with other residents) and were thought more likely to take action and inform the police about minor incidents of crime and disorder. However, this trend appears to stop in relation to street drug dealing and offences involving OC, as the control group respondents no longer reported their residents as the most likely to intervene. The reason for this finding was not explored, although several studies 
hypothesize the impact of explicit and implicit OCG intimidation (Crocker et al. 2017). Indeed, the finding that respondents generally reported their residents were less likely to personally intervene in scenarios attributed with the process of OC (street drug dealing) or specific OCGs, supports this assertion. However, importantly, even communities with a high OCG concentration can be differentiated from one another. Whilst this suggests community engagement practice should be tailored to the dynamics of the location, it also warrants further research to establish what differentiates the more resilient communities.

Second, the findings suggest a community interprets and responds to illegal incidents in different ways. Overall respondents thought the average citizen from their neighborhoods would take no action in $10 \%-48 \%$ of cases (median $=21 \%$ ), with their level of apathy or engagement being dependent on the specific incident. So, for example, a non-crime issue, such as truancy is thought to elicit fewer responses across all geographic areas. This prioritization process extends across incident genres. For example, whilst $80 \%$ of respondents felt a neighbourhood OCG dealing in class A drugs would generate a response from the average citizen, hearing about an OCG involved in counterfeit goods would generate a response from $71 \%$. The method of response is also associated with the incident. For example, whereas $27 \%$ felt the average citizen would personally confront someone they thought was assaulting a resident, only $3 \%$ felt they would confront individuals involved in drug dealing. These findings suggest a nuanced picture, as to whether a citizen will respond to crime and how that intervention will take place. A greater understanding of these issues will assist in establishing more effective practices to encourage more people to come forward with information.

Finally, whilst police officers intuitively identify areas that are difficult to police, this study provides a systematic methodology to document this difference. As illustrated, evidence can be provided to show whilst specific communities may be demographically similar, they can generate different community attitudes (in this study it was area A). Even though such areas may report less crime, they are consistently less likely to contact public authority figures or respond to crime - what Corkrean (2013) referred to as a conflict community. As such the ability of the police to obtain information or gain cooperation from the public may be dependent on the location rather than their professional competence. As police agencies in developed societies base their effectiveness on the consent and cooperation of the public (Myhill and Quinton 2011), this is a significant issue. Further, the most challenging communities are often associated with 'no go' areas, or erupt in disorder and demand significant resources. One of the implications of this type of research, is therefore to stimulate more sophisticated operational approaches to evaluate community perspectives. This understanding will assist policy makers and practitioners in proactively targeting their resources to assist in the development of more resilient, cooperative and collaborative communities. It will also assist others to understand the challenging nature that policing some of these areas can create.

Acknowledgements The Community Survey was designed with help from Temple University, Philadelphia, who have engaged in significant research regarding community consultation in policing. It was also supported by other research in the US, specifically discussions with Chief Corkrean (Granville PD, West Virginia). As stated it could not have been achieved without the assistance of the representatives from the UK police force involved who, as agreed, remain anonymous for this article. 


\section{Compliance with ethical standards}

Ethical approval All procedures performed in studies involving human participants were in accordance with the ethical standards of the institutional and national research committee and with the 1964 Helsinki declaration and its later amendments or comparable ethical standards. Informed consent was obtained from all individual participants included in the study. This article does not contain any studies with animals performed by any of the authors. Although no funding directly supported this research, the study cited here emanated from a wider evaluation project conducted in the Police Force area. The Police Force provided a small level of funding to support this wider research project.

Conflict of interest Stuart Kirby declares that he has no conflict of interest.

Michelle McManus declares that she has no conflict of interest.

Laura Boulton declares that she has no conflict of interest.

Open Access This article is distributed under the terms of the Creative Commons Attribution 4.0 International License (http://creativecommons.org/licenses/by/4.0/), which permits unrestricted use, distribution, and reproduction in any medium, provided you give appropriate credit to the original author(s) and the source, provide a link to the Creative Commons license, and indicate if changes were made.

\section{References}

Bolling K, Grant C, Sinclair P (2007) British crime survey of England and Wales 2006/07. Online report. http://www.esds.ac.uk/doc/5755/mrdoc/pdf/5755techreport_vol2. Accessed 2 August 2015

Bottoms A (2012) Developing socio-spatial criminology. In: Maguire M, Morgan R, Reiner R (eds) The Oxford handbook of criminology. Oxford University Press, Oxford

Bullock K, Chowdhury R, Hollings P (2013) Public concerns about organised crime. Home Office Research Report 16, London

Cantle T (2001) Community Cohesion: A report of the independent review team. London: Home Office

Clarke RVG, Eck JE (2003) Crime analysis for problem solvers: in 60 small steps. US Department of Justice, Washington

Corkrean J (2013) Situational policing in rural areas', The Police Chief, 80 (11), http://www.policechiefmagazine. org/magazine/index.cfm?fuseaction=display_arch\&article_id=3190\&issue_id=112013. Accessed 20 September 2015

Crocker R, Garner S, Webb S, \& Skidmore M (2017) The impact of organised crime in local communities, http://www.police-foundation.org.uk/uploads/holding/projects/impact_of_oc_on_local_communities.pdf. Accessed 2 July 2017

De Barnier V (2014) Counterfeiting: the challenge for governments, companies and consumers. In: Gill M (ed) The handbook of security, 2nd edn. Palgrave Macmillan, Basingstoke

Department for Environment, Food and Rural Affairs (DEFRA), Indices of Deprivation (2015) http://www. gov.uk/government/statistics/english-indices-of-deprivation-2015. Accessed 2 July 2017

Department of Children and Youth Affairs (2016) Lifting the lid on Greentown. Department of Children and Youth Affairs, Dublin

Finkenauer JO (2005) Problems of definition: what is organized crime? Trends in Organized Crime 8(3):63-83

Frone M (2013) Alcohol and illicit drug use in the workforce and workplace. Washington: American Psychological Association.

Gavin Hales, Dick Hobbs, (2010) Drug markets in the community: a London borough case study. Trends in Organized Crime 13 (1):13-30

Gilmour S (2008) Understanding organized crime: a local perspective. Policing 2(1):18-27

Hales J, Nevill C, Pudney S, Tipping S (2009) Longitudinal analysis of offending, crime \& justice survey 2003-06. Home Office, London

Harocopos A, Hough, M (2005) Drug dealing in open air markets. Problem-Oriented Guides for Police.Problem Specific Guides Series, 31. Washington, DC: US Department of Justice. Office of Community Oriented Policing Services. 
Home Office (2013) Serious and organised crime strategy. Online at http://www.gov. uk/government/publications/serious-organised-crime-strategy. Accessed 29 November 2017

Innes M, Fielding N (2002) From community to communicative policing: signal crimes and the problem of police reassurance. Sociological Research online 7(2), http://www.socresonline.org.uk/7/2/Innes.html. Date Accessed 11 August 2014

Kennedy LW, Caplan JM, Piza E (2010) Risk clusters, hotspots, and spatial intelligence: risk terrain modeling as an algorithm for police resource allocation strategies. J Quant Criminol 27(3):339-362

Kirby S, Francis B, Humphreys L (2016) Using the UK general offender database as a means to measure and analyse organised crime. Policing: Int J Police Strateg Manag 39(1):78-94

Kirby S, Snow N (2016) Praxis and the disruption of organised crime groups. Trends Organised Crime 19(2): $111-124$

Kubrin CE, Weitzer R (2003) New directions in social disorganization theory. J Res Crime Delinq 40(4):374-402

Levi M, Maguire M (2004) Reducing and preventing organised crime: an evidence based critique, Crime, Law and Social Change, 41(5), 397-469

Levine M, Cassidy C, Brazier G (2002) Self categorization and bystander non intervention: two experimental studies. J Appl Soc Psychol 32(7):1452-1463

Lupton R, Wilson A, May T, Warburton H, Turnball P (2002) A rock and a hard place: driug markets in deprived neighbourhoods. Home Office research study 240. London: Home Office.

May T, Edmunds M, Hough M (1999) Street Business: The links between sex and drug markets. London: Home Office.

Myhill A, Quinton P (2011) It's a fair cop? Police legitimacy, public cooperation and crime reduction: an interpretive evidence commentary. NPIA, Wyboston

NCA (2017) National strategic assessment of Serious and Organised Crime 2017, http://www. nationalcrimeagency.gov.uk/publications/807-national-strategic-assessment-of-serious-and-organisedcrime-2017/file. Accessed 29 November 2017

Rosenthal R (1963) Experimenter attributes as determinants of Subjects' responses. J Pers Assess 27(3):324-331

Sampson RJ (2004) Neighbourhood and community: collective efficacy and community safety. New Economy 11:106-113

Sampson RJ, Groves WB (1989) Community structure and crime: testing social disorganization theory. Am J Sociol 94(4):774-802

Serious Crime Act (2015) http://www.legislation.gov.uk/ukpga/2015/9/contents/enacted. Accessed 28 November 2017

Shaw C, McKay M (1942) Juvenile delinquency and urban areas. University of Chicago Press, Chicago

Sherman L, Gartin P, Buerger M (1989) Hot spots of predatory crime: routine activities and the criminology of place. Criminology 27:27-56

Skogan WG, Hartnett SM (1997) Community policing. Oxford University Press, Chicago Style, New York

The Guardian (2016) Britain's trust deficit is getting worse - but we all have faith in nurses. http://www. theguardian.com/politics/2016/dec/03/poll-uk-trust-deficit-getting-worse-politicians-teachers-nurses. Accessed 29 November 2017

Tuffin R, Morris J, Poole A (2006) An evaluation of the impact of the National Reassurance Policing Programme, Home Office research study 296. Home Office, London

van Dijck M (2007) Discussing definitions of organised crime: word play in academic and political discourse. Humsec J 1(1):65-90

von Lampe K (2017) Definitions of organized crime. Available at http://www.organised-crime. de/organizedcrimedefinitions.htm. Accessed 8 Jan 2017

Weisburd D, Davis M, Gill C (2015) Increasing collective efficacy and social capital at crime hot spots: New crime control tools for the police. Policing 9(3):265-274

Wilson JQ, Kelling GL (1982) Broken windows. The Atlantic Online, http://www.lantm.lth. se/fileadmin/fastighetsvetenskap/utbildning/Fastighetsvaerderingssystem/BrokenWindowTheory.pdf. Accessed 15 September 2015 